\title{
Co-relation Between Pulmonary Function Test and Quality Of Life In ObeseChildren
}

\author{
Dr. Sneha. D. Ghuman ${ }^{(1)}$, Dr. Sumitra Sakhwalkar ${ }^{(2)}$, Dr. Snehal Ghodey ${ }^{(3)}$ \\ 1. Assistant Professor MAEER'S Physiotherapy College India \\ 2.Assistant Professor MAEER'S Physiotherapy College India \\ 3. Principal MAEER'S Physiotherapy College India \\ ${ }^{(1,2,3)}$ Physiotherapy Department Maeer's Physiotherapy College, India
}

\begin{abstract}
Obesity is a chronic disease characterized by excessive body fat that cause damage to the individual's health and is associated with co-morbidities. Obesity can cause various deleterious effects to respiratory function.Obese children are at risk for psychological and social adjustment problems, including lower perceived competencies than normative samples on social, athletic and appearance domain as well as overall self worth.A trend towards decreased physical activity levels due to the increasingly sedentary nature of recreation, changing modes of transportation, and increasing urbanization. And since in obesity physical activity is reduced, there are chances of depression and decreased QUALITY OF LIFE.Procedure: Samples were selected as per inclusion and exclusion. Written consent was taken and permission from the school was taken. Procedure was explained to them.PULMONARY FUNCTION TEST was recorded using a PULMONARY FUNCTION TEST machine, one trial was given prior to recording the final readings. Height was measured with the help of measuring tape and weight was recorded with the weighing machine and BMI was calculated and percentile was recorded. Peds- QUALITY OF LIFE questionnaire was distributed among the students and was filled by the students and collected..Data was collected and analyzed using unpaired t test and co-relation was found using Instat software. Result: The $\mathrm{p}$ value for QUALITY OF LIFE in obese and non-obese is $<0.001$ highly significant and $t$ value is 3.167 .Fev1/ FVC was significant with $p$ value 0.0068 and $t$ value is 4.170 Conclusion: PULMONARY FUNCTION TEST and QUALITY OF LIFE are reduced in obese children.
\end{abstract}

\section{INTRODUCTION}

Obesity is a chronic disease characterized by excessive body fat that causes damage to the individual's health and is associated with co morbidities. ${ }^{(1)}$ Obesity can cause various deleterious effects to respiratory function, such as alterations in respiratory mechanics, decrease in respiratory muscle strength and endurance, decrease in pulmonary gas exchange, lower control of breathing, and limitations in pulmonary function tests and exercise capacity. These changes in lung function are caused by extra adipose tissue in the chest wall and abdominal cavity, compressing the thoracic cage, diaphragm, and lungs. The consequences are a decrease in diaphragm displacement, a decrease in lung and chest wall compliance, and an increase in elastic recoil, resulting in a decrease in lung volumes and an overload of inspiratory muscles. These changes are worsened by an increase in the BMI.Obesity can cause deleterious effects on respiratory function and impair health and quality of life. ${ }^{(2)}$ Obese children are at risk for psychological and social adjustment problems, including lower perceived competencies than normative samples on social, athletic and appearance domain as well as overall self worth. Quality of life is a more comprehensive and multidimensional construct and includes physical, emotional, social and school functioning. ${ }^{(7)} \mathrm{A}$ trend towards decreased physical activity levels due to the increasingly sedentary nature of many forms of recreation time, changing modes of transportation, and increasing urbanization. Being overweight during childhood and adolescence increases the risk of developing high cholesterol, hypertension, respiratory ailments, orthopedic problems, depression. The aim of the study was to find out co-relation between QUALITY OF LIFE \& Pulmonary function test in obese and non-obese school going children. The objectives of the study was (1) To assess Quality of Life in obese children. (2)To assess Pulmonary Function Test in obese children. (3)To find out co-relation between Pulmonary Function Test \& Quality of Life in obese children. Inclusion: (1)Both girls and boys (2)Age 8-12 YRS (3)Obese and non- obese children (4)Obese: 95 percentile and above Exclusion: Having any respiratory condition

\section{Procedure:}

Samples were selected as per inclusion and exclusion. Written consent was taken and permission from the school was taken. Procedure was explained to them.PULMONARY FUNCTION TEST was recorded using 
a PULMONARY FUNCTION TEST machine, one trial was given prior to recording the final readings.Height was measured with the help of measuring tape and weight was recorded with the weighing machine and BMI was calculated and percentile was recorded.Peds QOL questionnaire was distributed among the students and was filled by the students and collected. Data was collected and analyzed using unpaired t test and co-relation between PFT \& QOL was found using pearsons co-relation using Instat software.

\section{RESULT}

The $\mathrm{p}$ value for QUALITY OF LIFE in obese and non-obese is $<0.001$ highly significant and $\mathrm{t}$ value is 3.167 . FEV1/ FVC was significant with p value 0.0068 and $t$ value is 4.170 in obese students. There was negative corelation between QUALITY OF LIFE and Pulmonary Function Test

\section{GRAPHS}

\section{GRAPH 1}

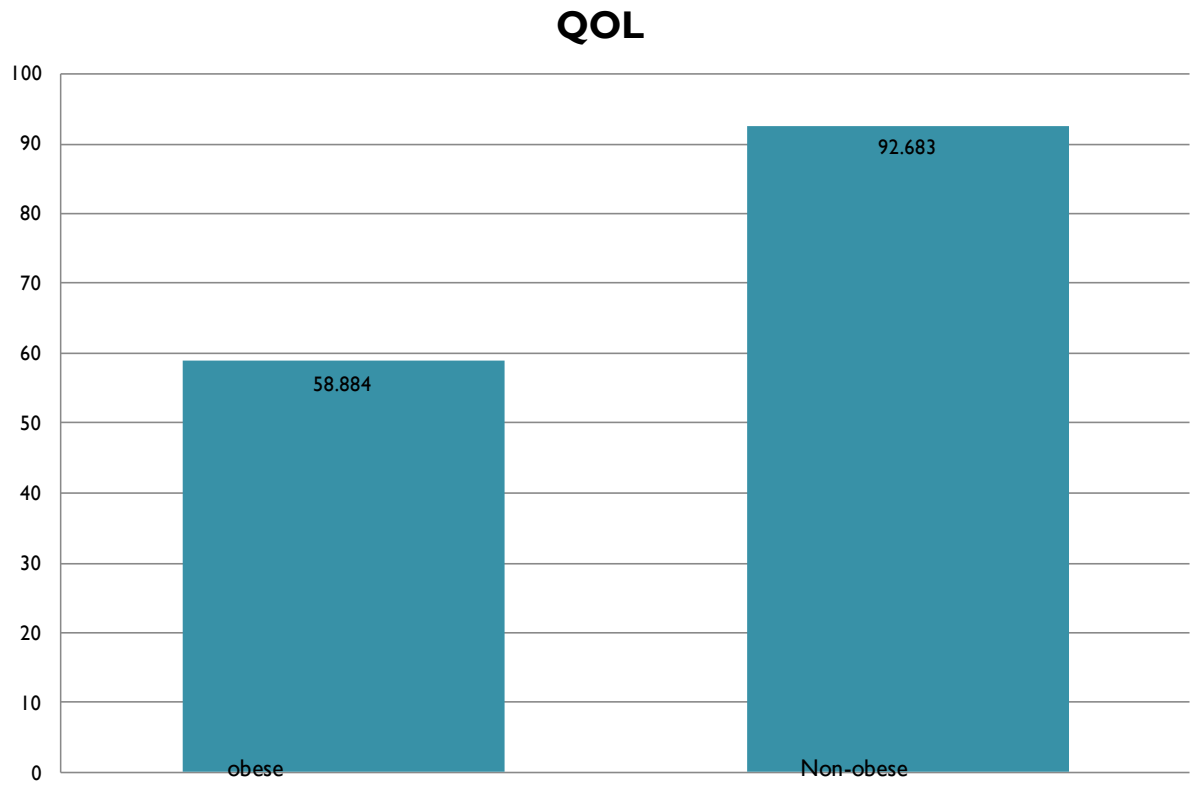

The $\mathrm{p}$ value is $<0.001$ significant and t value is 3.167

GRAPH 2

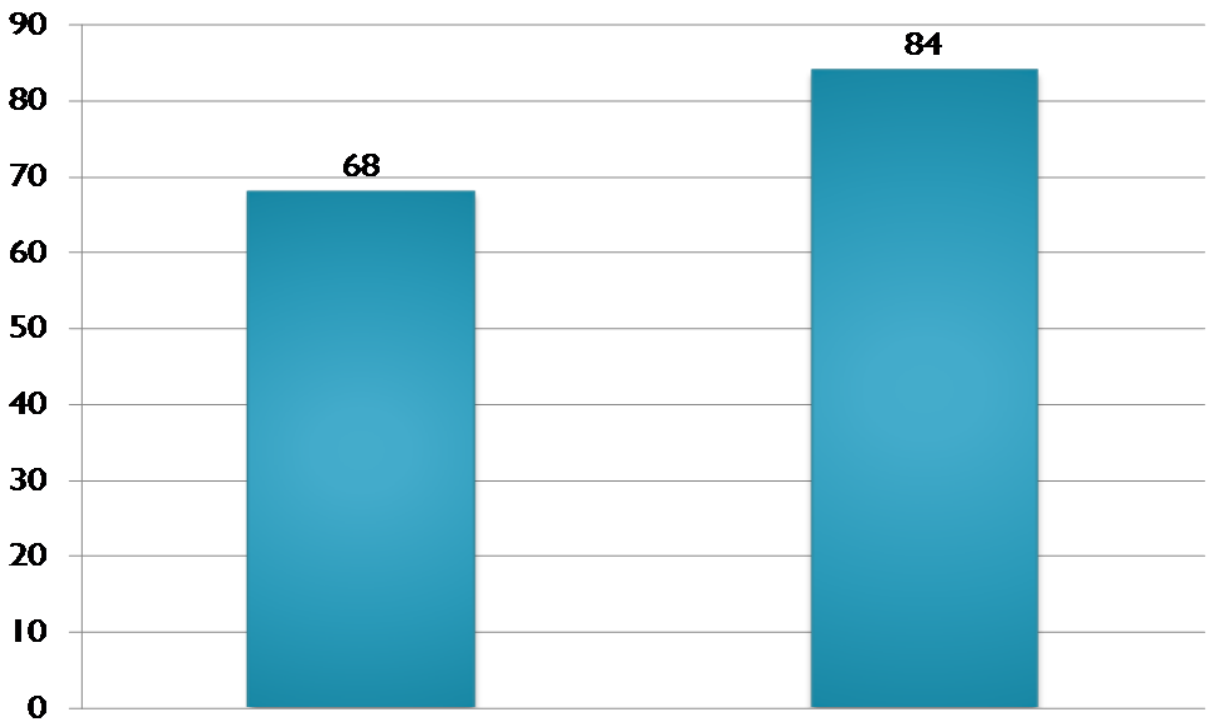

The $p$ value is 0.0068 significant and $t$ value is 4.170

\section{GRAPH 3}


Co-relation between PFT and QOL

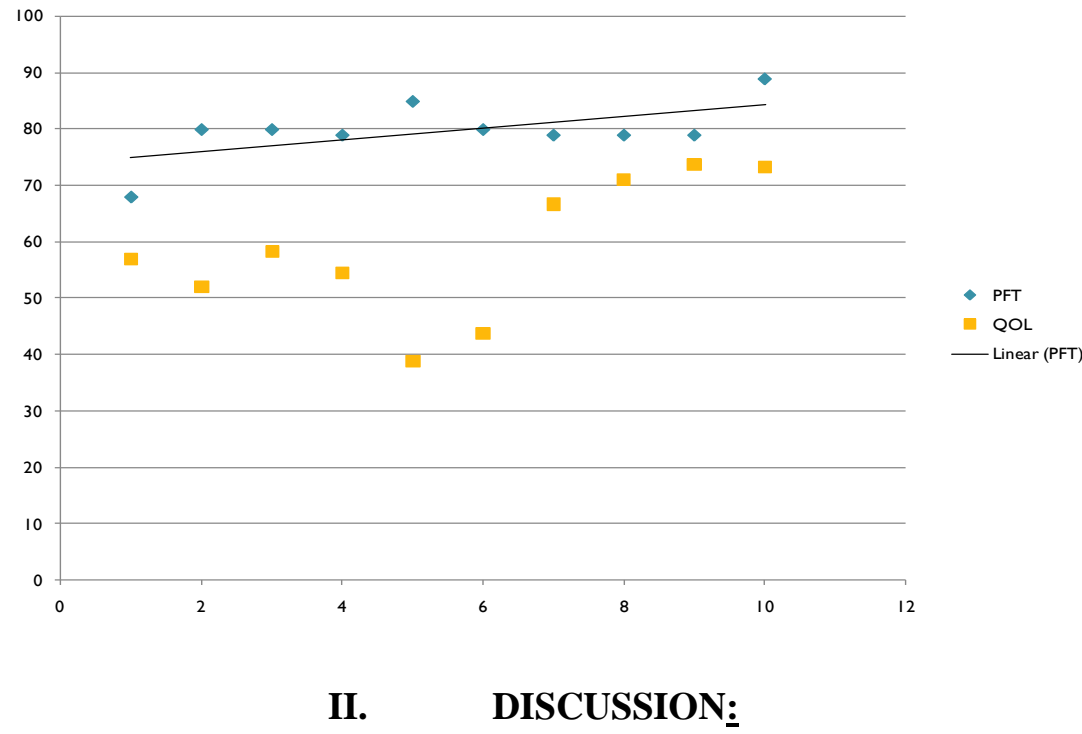

The study was conducted to find assess Quality of Life in obese children\&Pulmonary Function Test in obese children. To find out the co-relation between Pulmonary Function Test \& Quality of Life in obese children. The result of study indicates that QOL is decreased in obese children and there is a negative corelation between pulmonary function test and QOL of obese children. Obesity has effects on lung function that can reduce respiratory well-being, even in the absence of specific respiratory disease, and may also exaggerate the effects of existing airway disease. Obese people are at increased risk of respiratory symptoms, such as breathlessness, particularly during exercise, even if they have no obvious respiratory illness.Obesity has a clear potential to have a direct effect on respiratory well-being, since it increases oxygen consumption and carbon dioxide production, while at the same time it stiffens the respiratory system and increases the mechanical work needed for breathing. QUALITY OF LIFE is compromised in obese children as compared to non- obese children.The study indicates that although physical and social functions are decreased, less decrement in emotional status and minimal impairment in school functioning.It was observed once the child is identified as obese, they have reduced psychosocial functioning as compared to normal.Changes in emotional and psychological aspect is due to lack of family support, teasing or bullying by peers.Psychosocial aspects of obesity are often ignored in order to improve physical health are important in children.Psychosocial and emotional status is disturbed due to the continuous pressure by parents about their appearance and bullying by peers and less participation in social and athletic activities.Obese and overweight children in our study had impaired physical functioning. We observed that the BMI was inversely correlated with physical functioning. This supports the idea that the diminished ability to move with increasing weight leads to a decrease in caloric expenditure with the potential consequence of a further mismatch in energy balance leading to additional weight ${ }^{(10)}$ This all components leads to decreased QUALITY OF LIFE in obese children.Obesity results in spirometric variables decrease in proportion to lung volumes, but are rarely below the normal range, even in the extremely obese, while reductions in expiratory flows and increases in airway resistance are largely normalized by adjusting for lung volumes. The total respiratory compliance in obesity is reduced. This results from the effect of excess truncal fat mass, increased pulmonary blood volume and increased closure of the dependent airways of patients who are obese. These physiologic changes are more pronounced during recumbency in patients who are obese compared with normal-weight patients.Severely obese patients may also demonstrate inefficiency of the respiratory muscles, particularly the diaphragm. Hence Pulmonary function is decreased in obese children. Thus the study concludes that Quality of life and Pulmonary function test is decreased in obese children

\section{CONCLUSION :}

PULMONARY FUNCTION TEST \& QUALITY OF LIFE is reduced in obese children

\section{REFERENCES:}

[1] Quality of Life, Motor Ability, and Weight Status among School-aged Children of Tehran

[2] F Khodaverdi,1 A Bahram,2,* and M Asghari Jafarabadi3 Iran J Public Health. 2012; 41(6): 97102.Published online 2012 June

[3] Global Strategy on Diet, Physical Activity and Health, WHO 2010 
[4] Influence of Race, Ethnicity, and Culture on Childhood Obesity: Implications for Prevention and Treatment, ${ }^{1}$ Stephen R et al, 2008 November; 31(11): 2211-2221

[5] Health related QOL in obese children and adolescent JAMA April 92003 vol-289-13

[6] The effects of obesity on pulmonary function A M Li, D Chan, E Wong, J Yin et al, Arch Dis Child 2003;88:361-363

[7] Health-related quality of life in a clinical sample of obese children and adolescents,Afsane Riazi1*, Sania Shakoor2, Isobel Dundas3, Christine Eiser4, Sheila A McKenzie3 Riazi et al. Health and Quality of Life Outcomes 2010, 8:134.

[8] Health related Quality of life of severely obese children \& adolescent Jefferey B Schwimmer ,Tasha M Burwinkle, James W Warni, JAMA2003,289-1813-1819

[9] Jonides L, Buschbacher V, Barlow SE. Management of child and adolescent obesity: psychological, emotional, and behavioral assessment. Pediatrics.2002;110:215-221.2.

[10] Dietz WH. Health consequences of obesity in youth: childhood predictors of adult disease. Pediatrics.1998;101:518-525.3.

[11] Banis HT, Varni JW, Wallander JL. et al. Psychological and social adjustment of obese children and their families. Child Care Health Dev.1988;14:157-173.

[12] Guo SS, Huang C, Maynard LM. Body mass index during childhood, adolescence and young adulthood in relation to adult overweight and adiposity: the Fels Longitudinal Study. Inter J Obes. 2000;24:1628-3

[13] Fiveash LB. 2003. The relationship among obesity, QOL, and health care in African American school children: [PhD thesis]. The University of Alabama at Birmingham.

[14] Institute of Medicine . Preventing childhood obesity: Health in the balance. Washington DC: National Academies; 2004.

[15] Whitlock EP, Williams SB, Gold R, Smith PR, Shipman SA. Screening and interventions for childhood overweight: A summary of evidence for the US preventive services task force. Pediatrics. 2005;16:12544. 